\title{
Effect of High Dose Active Vitamin D Therapy on the Development of Hypocalcemia After Subtotal Parathyroidectomy in Patients on Chronic Dialysis
}

\author{
Malina Grube' \\ Frank Weber ${ }^{2}$ \\ Anna Lena $\mathrm{Kahl}^{3}$ \\ Andreas Kribben' \\ Nils Mülling (D' \\ Walter Reinhardt' \\ 'Department of Nephrology, University \\ Hospital Essen, Essen, Germany; \\ ${ }^{2}$ Department of General-, Visceral- and \\ Transplantation Surgery, Section of \\ Endocrine Surgery, University Hospital \\ Essen, Essen, Germany; ${ }^{3}$ Institute of \\ Medical Psychology and Behavioral \\ Immunobiology, University Hospital \\ Essen, Essen, Germany
}

Correspondence: Nils Mülling Department of Nephrology, University Hospital Essen, Hufelandstr. 55, Essen, 45I47, Germany

Email nils.muelling@uk-essen.de
Background: The period after parathyroidectomy (PTx) in dialysis patients is characterized by periods of severe hypocalcemia. This study aims to investigate the effect of high doses of active vitamin D immediately after PTx on the development of hypocalcemia.

Materials and Methods: We retrospectively reviewed 111 patients with secondary hyperparathyroidism receiving subtotal PTx between 2010 and 2019. A high dose group "HDG" $(\mathrm{n}=67)$ receiving $12 \mu \mathrm{g}$ alfacalcidol in combination with $8.550 \mathrm{mg}$ calcium acetate per day, which was then adapted according to lab values, was compared with a low dose group "LDG" $(n=44)$ receiving up to $4 \mu \mathrm{g}$ alfacalcidol per day. The laboratory values were recorded up to ten weeks postoperatively.

Results: The assumed drops in parathyroid hormone (PTH) and calcium were observed in both groups after PTx. We observed significantly lower calcium values in the LDG between days 4 and 18 postoperatively than in the HDG $(p<0.001)$. The proportion of severe hypocalcemia after PTx (total calcium $<1.5 \mathrm{mmol} / \mathrm{l}$ ) in the HDG was $8.5 \%$ on day 1 and $47 \%$ on day 4 in the LDG. Intravenous calcium requirements were significantly lower in the HDG $(7.6 \%)$ than in the LDG $(45.7 \% ; p=0.001)$.

Conclusion: The period after PTx in dialysis patients is characterized by an expected drop in PTH and calcium within the first days. Ongoing high turnover is observed in the 2 nd and 3rd week after PTx. Administering high doses of alfacalcidol combined with calcium acetate diminishes the episodes of severe hypocalcemia and the need for intravenous calcium.

Keywords: secondary hyperparathyroidism, hungry bone disease, parathyroidectomy, vitamin $\mathrm{D}$, dialysis, CKD stage 5

\section{Introduction}

Secondary hyperparathyroidism (sHPT), an endocrine regulation disorder of the parathyroid gland caused by chronic kidney disease (CKD), develops in almost all patients suffering from end stage renal disease. ${ }^{1}$ It is the result of low $1.25(\mathrm{OH}) 2$ Vitamin D levels, hypocalcemia and phosphate retention. Patients suffering from sHPT suffer from an increased mortality- and carry a higher risk for fractures, anemia, hypertension, morbidities like bone pain, itching and sexual dysfunction. Higher hospitalization rates due to cardiovascular and fracture related events are also observed. ${ }^{2,3}$ Renal osteodystrophy occurs through the stimulation of osteoclasts and osteoblasts which results in increased bone resorption, and as too little bone is formed to compensate for bone resorption, patients develop the clinical manifestation of "osteitis fibrosa" or "osteodystrophy". 4 
In addition to dietary options, various drugs such as phosphate chelators, vitamin D supplements and calcimimetics are available to treat sHPT. ${ }^{5}$ In most patients SHPT can be controlled by medication, but there are still about $4-14.3 \%$ who are refractory to medical therapy and need parathyroidectomy (PTx) to effectively lower calcium, phosphate and parathyroid hormone (PTH) levels. ${ }^{6,7}$ The current KDIGO CKD-MBD guideline recommends PTx for severe sHPT (persistent PTH $>800 \mathrm{pg} / \mathrm{mL}$ ) with hypercalcemia $(>2.54 \mathrm{mmol} / \mathrm{l})$ or hyperphosphatemia $(>$ $2.1 \mathrm{mmol} / \mathrm{l}$ ), as well as for severe clinical symptoms such as pruritus, muscle and bone pain and extraosseous calcification. ${ }^{5}$ Moreover, persistent HPT after kidney transplantation is associated with increased mortality. ${ }^{8}$

The sudden withdrawal of PTH causes an increased absorption of calcium and phosphate from the circulation into the bone leading to profound hypocalcemia, a condition termed "Hungry-Bone-Syndrome" (HBS). ${ }^{9}$ Managing hypocalcemia at the early postoperative stage is complicated because precise and effective pre-operative assessments of calcium deficiency have not been established and there is no consistent recommendation for postoperative treatment. ${ }^{10,11}$ Excessive preoperative levels of PTH, alkaline phosphatase (AP) and bone specific AP, low levels of calcium and albumin and young age were recently identified as risk factors for postoperative hypocalcaemia. ${ }^{12-14}$ The administration of calcium supplements and active vitamin D to increase intestinal calcium absorption has long been standard in treating and preventing hypocalcemia after PTx. ${ }^{11,15-17}$ Moreover, bisphosphonates were effective lowering the incidence of HBS. ${ }^{18}$ Nevertheless $28-71 \%$ develop HBS. ${ }^{9,19}$ A positive effect on preventing hypocalcemia via the application of active vitamin D is reported in the current literature. Authors have studied the effect of different doses of active vitamin D but to our knowledge there are no data on the effect of using doses exceeding $4 \mu \mathrm{g}$ per day. ${ }^{20,21}$

The purpose of this study was to investigate the influence of high-dose active vitamin D medication, ie $12 \mu \mathrm{g}$ alfacalcidol per day in combination with calcium acetate, on the postoperative course of PTH, calcium, phosphate and AP within the first ten weeks after PTx.

\section{Materials and Methods}

\section{Patients}

In this single center retrospective study, we reviewed the hospital files (by ICD-9/ICD-10 and manual review) of
111 patients who had undergone PTx between 2010 and 2019. Extracted information included demographic data, modality and duration of dialysis treatment and underlying kidney disease. Biochemical course of serum total calcium, phosphate, AP and PTH were recorded once prior to surgery and for a 10 -week period after surgery. Data on operative technique and histology of parathyroid glands were extracted from surgical and pathology reports. The duration of the hospital stay was calculated from the preoperative day until day of dismission.

The study was approved by the local ethics committee of the University Duisburg-Essen (16-70-40-BO). This study was conducted in accordance with the Declaration of Helsinki.

\section{Perioperative Treatment Strategy}

Medications were recorded preoperatively and postoperatively. Vitamin D supplements (cholecalciferol, calcitriol, alfacalcidol), phosphate chelators (lanthanum carbonate, sevelamer and calcium containing phosphate chelators), calcimimetics (cinacalcet) and the number of patients who received i.v. calcium postoperatively were registered.

The HDG was treated postoperatively according to a fixed schedule of $12 \mu \mathrm{g}$ alfacalcidol and $8550 \mathrm{mg}$ calcium acetate (950 mg TID) on the day of surgery up to two days after PTx. The daily dosage of alfacalcidol and calcium acetate was adjusted gradually over time. Additional intravenous calcium was applied when clinical symptoms like paresthesia, muscle spasms, cramps, tetany, circumoral numbness, and seizures appeared.

The LDG received different combinations of active vitamin $\mathrm{D}(0.25 \mu \mathrm{g}$ to $4 \mu \mathrm{g}$ per day), phosphate chelators and calcium supplements. The first 19 patients were treated according to the LDG protocol. However, in these patients a high prevalence of hypocalcemia occurred. Then, in three patients (data not included in study) the dose of alfacalcidol was increased to $6 \mu \mathrm{g}$, but one could neither see a relevant improvement in hypocalcemia nor in the occurrence of hypercalcemia. Therefore, the alfacalcidol- and calcium acetate doses (according to the protocol) were increased. Thus, the coming 52 patients were treated either in the LDG $(n=25)$ or HDG $(n=27)$ and the remaining 41 patients were in the HDG group.

Prior to surgery, all patients were examined by ultrasound whereby the volume and number of hyperplastic parathyroid glands was measured. About half of the patients were additionally screened via Tc $99 \mathrm{~m}$ scintigraphy. 


\section{Parathyroidectomy}

The indication for PTx was established because of sHPT in patients (with long standing renal insufficiency), that was not adequately treatable with medication (ie elevated PTH levels in the presence of maximal management with vitamin D analogues, phosphate chelators and/or cinacalcet). Since 2014, it has become the standard of care to perform subtotal PTx without transcervical partial thymectomy. Patients prior to this year received either total PTx with auto transplantation or subtotal PTx. For subtotal PTx all 4 glands where identified and $3 \frac{1}{2}$ glands where resected, leaving a volume of about $8 \times 8 \mathrm{~mm}$ parathyroid tissue with preserved blood supply. Resected tissue was validated by frozen section procedure. For total PTx, all four parathyroid glands were identified and resected. The tissue from the least hyperplastic gland was fragmented and transplanted into the brachioradial muscle of the non-shunt arm. The serum parathyroid hormone level was assessed intraoperatively to monitor the surgical success.

\section{Statistical Analysis}

Our data analysis was performed using the program PASW Statistics (Version 22, SPSS, Chicago, IL, USA). Due to missing data, the sample size is always provided for the various parameters.

For the comparison between the groups MannWhitney- $U$-Test and chi-square test were used. Changes over time within the groups were investigated using the Wilcoxon test. For postoperative drop, we compared the first postoperative day with the preoperative day; for all other changes within the 10 weeks the first postoperative day was taken as the reference value. Bonferroni correction was applied for multiple comparisons. The significance level was $p<0.05$ and for multiple comparisons $p<0.05 /$ number of comparisons.

\section{Results}

Demographics, basic clinical and biochemical data on the 111 patients are listed in Table 1. Patients were young (mean: 46.86 years) and stayed a long time on dialysis (mean: over 6 years). The proportion of patients with diabetic nephropathy as an underlying disease is low (1.8\%) as well as Diabetes as a comorbidity (13.45\%). Chronic Glomerulonephritis is with $36 \%$ the most prevalent underlying disease.

Patients had elevated pre-op PTH- (mean: 1417 $\mathrm{pg} / \mathrm{mL}$ ) and AP levels (mean: $231 \mathrm{U} / \mathrm{l}$ ) demonstrating high bone turnover.
Based on the postoperative treatment with alfacalcidol, the patients were divided into a "high-dose group" (HDG) consisting of 67 patients and a "low-dose group" (LDG) consisting of 44 patients. Classification into HDG and LDG is illustrated in Table 2. Basic clinical data did not differ between groups, only the number of kidney transplants differed significantly $\left(C h i^{2}(2)=9.631, p=0.006\right)$. The average duration of hospital stay was 5.52 days for the HDG and 6.95 days for the LDG $(U=-0.40, p=0.693)$. Although the average length of stay did not significantly differ, a larger proportion of LDG patients were discharged from hospital after eight days. In the LDG, about $23.08 \%$ of patients had to stay longer than eight days, with two patients staying for 12 days and one patient each for 19, 24 and 26 days, respectively. Only $4.84 \%$ in the HDG had to stay longer than eight days (those three patients were discharged after ten days).

\section{Calcium}

Preoperative calcium values in both groups exceeded the normal value: $2.39 \pm 0.25 \mathrm{mmol} / \mathrm{l}$ in the $\mathrm{HDG}$ and $2.52 \pm$ $0.25 \mathrm{mmol} / 1$ in the LDG. Postoperatively, the mean calcium value dropped to $1.93 \pm 0.34 \mathrm{mmol} / \mathrm{l}$ in the $\mathrm{HDG}(z=$ $-6.21, p<0.001)$ and to $1.99 \pm 0.31 \mathrm{mmol} / 1$ in the LDG $(z=-4.94 ; p<0.001)$ (Figure 1).

Within the HDG, the lowest average was measured on the first postoperative day at $1.93 \pm 0.34 \mathrm{mmol} / \mathrm{l}$. Thereafter, the mean value rose steadily, so that from the second postoperative day until the end of the observation period, the values fell within the normal range. We noted a significant increase compared to the first postoperative day on day $4(z=-3.02, p=0.002), 5-9$ $(z=-2.71, p=0.006)$ and $10-18(z=-3.15, p=0.001)$ and between week $3-5(z=-2.80, p=0.004)$ and 6-8 $(z=$ $-3.97, p<0.001)$. The lowest calcium value measured in one patient was $1.34 \mathrm{mmol} / \mathrm{l}$, the highest was $3.32 \mathrm{mmol} / \mathrm{l}$.

In the LDG, the mean calcium value dropped to $1.99 \pm$ $0.31 \mathrm{mmol} / 1$ on the first postoperative day. It continued to drop significantly to $1.58 \pm 0.37 \mathrm{mmol} / \mathrm{l}$ by the fourth postoperative day $(z=-3.07, p<0.001)$. The lowest calcium value was measured between days 5 and 9 at $1.00 \mathrm{mmol} / \mathrm{l}$, whereas the highest value was $2.86 \mathrm{mmol} / 1$.

The mean value in the HDG was significantly higher than the LDG's on the 4th $(z=-3.87, p<0.001)$, 5th-9th $(z=-2.99, p=0.002)$, and 10th-18th postoperative days $(z=-2.84, p=0.004)$.

To evaluate the hypo- as well as hypercalcemia more precisely, we classified the calcium values: a calcium value between 2.0-2.6 mmol/1 was considered normal. 
Table I Sociodemographic Data and Basic Biochemical Data of the Total Patient Collective

\begin{tabular}{|c|c|c|c|}
\hline & & $\mathbf{n}$ & \\
\hline Sex & $\begin{array}{l}\text { Male } \\
\text { Female }\end{array}$ & III & $\begin{array}{l}58.56 \%(65) \\
41.44 \%(46)\end{array}$ \\
\hline Age [years] & & 111 & $46.86 \pm 14.01$ \\
\hline BMI $\left[\mathrm{kg} / \mathrm{m}^{2}\right]$ & & 85 & $26.08 \pm 5.35$ \\
\hline Dialysis Modality & $\begin{array}{l}\text { HD } \\
\text { PD } \\
\text { Non }\end{array}$ & 96 & $\begin{array}{l}76.04 \%(73) \\
20.84 \%(20) \\
3.12 \%(3)\end{array}$ \\
\hline Duration of Dialysis [month] & & 91 & $74.04 \pm 64.11$ \\
\hline Underlying disease & $\begin{array}{l}\text { Glomerulonephritis } \\
\text { Cystic-dysplastic degeneration } \\
\text { Hypertensive nephropathy } \\
\text { Diabetic nephropathy } \\
\text { Tubular-interstitial nephropathy } \\
\text { Autoimmune vascular nephropathy } \\
\text { Cirrhotic kidney } \\
\text { Others or unknown }\end{array}$ & 111 & $\begin{array}{l}36.04 \%(40) \\
13.51 \%(15) \\
7.21 \%(8) \\
1.80 \%(2) \\
7.21 \%(8) \\
1.80 \%(2) \\
8.11 \%(9) \\
24.32 \%(27)\end{array}$ \\
\hline Transplantable & $\begin{array}{l}\text { No } \\
\text { Yes }\end{array}$ & 99 & $\begin{array}{l}21.21 \%(21) \\
78.79 \%(78)\end{array}$ \\
\hline Number of KTx prior to PTx & $\begin{array}{l}0 \\
1 \\
2\end{array}$ & 99 & $\begin{array}{l}68.69 \%(68) \\
23.23 \%(23) \\
8.08 \%(8)\end{array}$ \\
\hline Comorbidities & $\begin{array}{l}\text { Coronary heart disease } \\
\text { Arterial occlusive disease } \\
\text { Valvular insufficiency } \\
\text { Diabetes mellitus }\end{array}$ & 104 & $\begin{array}{l}23.07 \%(24) \\
6.73 \%(7) \\
10.57 \%(11) \\
13.46 \%(14)\end{array}$ \\
\hline Preoperative & $\begin{array}{l}\text { Calcium } \\
\text { Phosphate } \\
\text { PTH } \\
\text { AP }\end{array}$ & $\begin{array}{l}105 \\
47 \\
99 \\
69\end{array}$ & $\begin{array}{l}2.44 \pm 0.25 \mathrm{mmol} / \mathrm{l} \\
5.71 \pm 1.48 \mathrm{mg} / \mathrm{dl} \\
1417.44 \pm 791.17 \mathrm{pg} / \mathrm{mL} \\
231.35 \pm 246.79 \mathrm{U} / \mathrm{l}\end{array}$ \\
\hline
\end{tabular}

Notes: Data are given as mean \pm SD or as \% values (absolute number). Differences in the size of the collective are given as $n$.

Abbreviations: HD, haemodialysis; PD, peritoneal dialysis; PTx, parathyroidectomy; KTx, kidney transplantation.

Hypocalcemia was further categorized as mild $(1.7-2.0$ $\mathrm{mmol} / \mathrm{l})$, moderate $(1.5-1.7 \mathrm{mmol} / \mathrm{l})$ or severe $(<1.5$ $\mathrm{mmol} / \mathrm{l}$ ) and hypercalcemia was considered whenever values $>2.6 \mathrm{mmol} / \mathrm{l}$. Detailed examination revealed clear differences between groups over the course (Figures 2 and 3 ).

The highest rate of hypocalcemia $(<2.0 \mathrm{mmol} / \mathrm{l})$ within the HDG, was observed on the first day at $57.6 \%$, with the rate decreasing steadily, so that from the fourth postoperative day, most patients attained normal calcium values. The rate of severe hypocalcemia reached its $8.5 \%$ maximum on day one. Hypercalcemia occurred most frequently between days $10-18$, at $14.3 \%$.
We observed normal calcium values in the LDG on the first day $(45.7 \%)$ and in the sixth to eighth week $(50 \%)$ postoperatively. At all other time points, only between $11.8-38.5 \%$ of patients had calcium values of $2.0-2.6$ $\mathrm{mmol} / \mathrm{l}$. Most patients developed hypocalcemia $(<2.0$ $\mathrm{mmol} / \mathrm{l})$ on the fourth postoperative day (88.2\%). The proportion of patients with severe hypocalcemia increased to $47.1 \%$ on day four, accounting for the majority of hypocalcemia until day 18 . Overall, more than half of the patients $(53.8 \%)$ still had hypocalcemia after ten weeks, with $30.8 \%$ having severe hypocalcemia. The highest rate of hypercalcemia appeared after the fifth week at $8.3 \%$. 
Table 2 Sociodemographic Data and Information of Kidney Transplantations of HDG and LDG

\begin{tabular}{|c|c|c|c|c|c|c|}
\hline & & $\mathbf{n}$ & HDG & $\mathbf{n}$ & LDG & p-value \\
\hline Sex & $\begin{array}{l}\text { Male } \\
\text { Female }\end{array}$ & 67 & $\begin{array}{l}61.19 \%(4 I) \\
38.81 \%(26)\end{array}$ & 44 & $\begin{array}{l}54.55 \%(24) \\
45.45 \%(20)\end{array}$ & 0.556 \\
\hline Age [years] & & 67 & $46.87 \pm 12.24$ & 44 & $46.86 \pm 16.50$ & 0.944 \\
\hline BMI $\left[\mathrm{kg} / \mathrm{m}^{2}\right]$ & & 54 & $26.32 \pm 5.56$ & 31 & $25.64 \pm 5.01$ & 0.791 \\
\hline Transplantable & $\begin{array}{l}\text { No } \\
\text { Yes }\end{array}$ & 65 & $\begin{array}{l}21.54 \%(14) \\
78.46 \%(5 I)\end{array}$ & 34 & $\begin{array}{l}20.59 \%(7) \\
79.41 \%(27)\end{array}$ & 1.000 \\
\hline Number of KTx prior to PTx & $\begin{array}{l}0 \\
1 \\
2\end{array}$ & 65 & $\begin{array}{l}69.23 \%(45) \\
23.07 \%(15) \\
7.69 \%(5)\end{array}$ & 34 & $\begin{array}{l}67.64 \%(23) \\
23.53 \%(8) \\
8.82 \%(3)\end{array}$ & 1.000 \\
\hline Dialysis Modality & $\begin{array}{l}\text { HD } \\
\text { PD } \\
\text { Non }\end{array}$ & 63 & $\begin{array}{l}76.19 \%(48) \\
19.05 \%(12) \\
4.76 \%(3)\end{array}$ & 33 & $\begin{array}{l}75.76 \%(25) \\
24.24 \%(8) \\
0.00 \%(0)\end{array}$ & 0.480 \\
\hline Duration of Dialysis [month] & & 60 & $79.35 \pm 64.76$ & 31 & $63.77 \pm 62.58$ & 0.162 \\
\hline
\end{tabular}

Notes: Sociodemographic parameters and number of kidney transplants were compared between "high dose group" and "low dose group" using Chi ${ }^{2}$ test for nominally scaled values and Mann-Whitney- $U$ test for interval scaled values, respectively. Data are given as mean \pm SD or as \% values (absolute number). Differences in the size of the collective are given as $\mathrm{n}$.

Abbreviations: HD, haemodialysis; PD, peritoneal dialysis; PTx, parathyroidectomy; KTx, kidney transplantation.

\section{Phosphate}

A significant drop in phosphate levels compared to the first postoperative day was only observed on the second postoperative day in the HDG $(z=-3.78, p<0.001)$ The lowest average was measured on the fourth postoperative day with $4.48 \pm 1.21 \mathrm{mg} / \mathrm{dl}$. Thereafter a continuous increase up to $5.76 \pm 2.18 \mathrm{mg} / \mathrm{dl}$ was observed until the tenth week. Within the LDG, there was no significant change postoperatively, but the mean values measured were within the reference range from the second postoperative day.

As seen in Figure 4, the LDG exhibited consistently lower phosphate levels approximating the reference range (2.7$4.5 \mathrm{mg} / \mathrm{dl}$ ) than the HDG. However, we noted a statistically significant difference between groups only in the sixth to eighth week postoperatively $(z=-2.80, p=0.004)$.

\section{Alkaline Phosphatase}

Both groups revealed a significant drop after the removal of their glands (Figure 5). The preoperative mean of HDG was $218.78 \pm 236.52 \mathrm{U} / 1$, dropped to $153.49 \pm 113.11 \mathrm{U} / 1$ on day one $(z=-2.76, p=0.005)$, increased slightly to $196.77 \pm$ $211.16 \mathrm{U} / 1$ on the second to fourth day $(z=-4.51, p=0.001)$ and to $306.57 \pm 337.25 \mathrm{U} / 1$ between day $5-18(z=-4.81, p=$ $0.001)$. The mean within the LDG significantly dropped from $256.48 \pm 269.89 \mathrm{U} / 1$ preoperatively to $200.93 \pm 256.15 \mathrm{U} / 1$ on the first day $(z=-2.52, p=0.008)$. We found patients in both groups presenting high AP levels until the end of the observation period. In the HDG seven out of 42 patients had AP values above $200 \mathrm{U} / 1$ with the highest being at $1007.00 \mathrm{U} / 1$ but in the LDG there were three patients out of 13 (one was at $314.00 \mathrm{U} /$ 1 , the second at $1206.50 \mathrm{U} / 1$ and the third at $1503.50 \mathrm{U} / \mathrm{l})$.

\section{Parathyroid Hormone}

PTx in both groups caused a significant decrease in PTH from $1538.10 \pm 758.47 \mathrm{pg} / \mathrm{mL}$ preoperatively to $109.69 \pm$ $254.38 \mathrm{pg} / \mathrm{mL}$ on the first postoperative day $(z=-5.86 ; p<$ $0.001)$ in HDG and from $1206.29 \pm 813.34 \mathrm{pg} / \mathrm{mL}$ to 117.29 $\pm 290.07 \mathrm{pg} / \mathrm{mL}(z=-2.67, p=0.004)$ in LDG. During the ten weeks there were no significant changes within the groups compared to the first postoperative day and the data revealed no significant differences between the groups (Figure 6). Still, 8 out of 111 patients (7\%) showed (a) persistent or (b) recurrent hyperparathyroidism.

Reasons for persistent disease were 1) supernumerary gland in the right carotid sheath (YB), 2) supernumerary gland in the right thyrohyoid ligament (AJ), 3) $78 \%$ intraoperative decrease and persistent disease until LD NTX with normalization thereafter (SF), 4) intrathymic extraligamentary localization (PG) and 5) left lower gland not identified (ZD).

After ten weeks, six out of 41 patients in the HDG had PTH values above $300 \mathrm{pg} / \mathrm{mL}(383 \mathrm{pg} / \mathrm{mL} ; 421 \mathrm{pg} / \mathrm{mL}$; $433 \mathrm{pg} / \mathrm{mL} ; 490 \mathrm{pg} / \mathrm{mL} ; 1083 \mathrm{pg} / \mathrm{mL} ; 1105 \mathrm{pg} / \mathrm{mL}$ ) and 


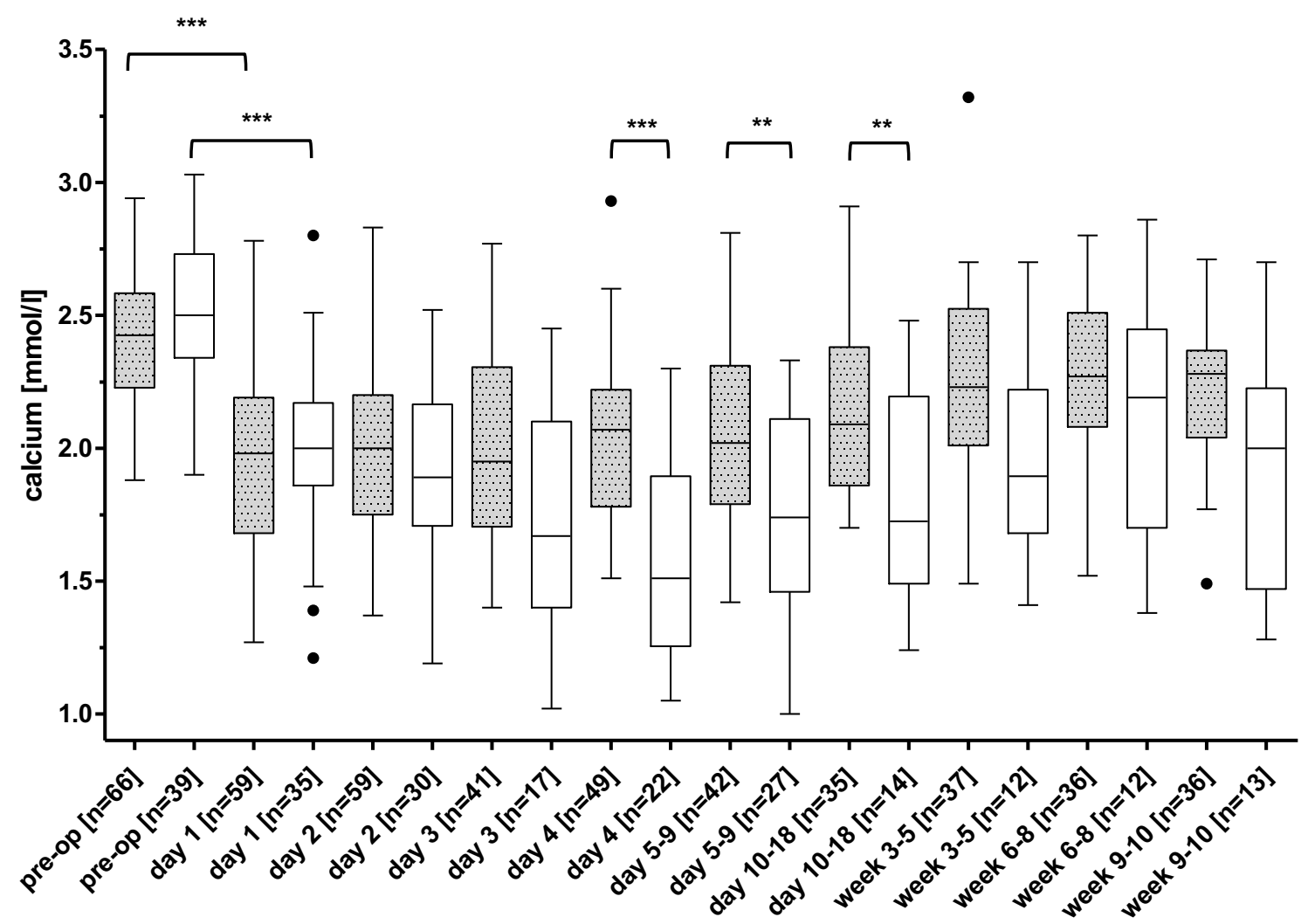

time [days/weeks]

Figure I Boxplot calcium course of the "high dose group" and "low dose group".

Notes: Black line = median; box = interquartile range; whisker = I.5 times IQR or minimum/maximum; dots = extreme outliers. "High dose group" is shown in grey; "Low dose group" is shown in white. Level of significance: *p $<0.05$; **p $<0.01$; ***p $<0.001$.

two out of 13 LDG patients were above $300 \mathrm{pg} / \mathrm{mL}$ ( 738 $\mathrm{pg} / \mathrm{mL} ; 2318 \mathrm{pg} / \mathrm{mL}$ ).

\section{Medication}

During the biochemical course, we were interested in the application of alfacalcidol and calcium supplements and therefore recorded the HDG's daily dose. As Table 3 shows, all patients received $12 \mu \mathrm{g}$ alfacalcidol until the second day. The first patients' doses could be reduced starting from the third day, and from day ten, their alfacalcidol could be discontinued. In the end, the average dose was reduced to $4.77 \pm 4.49 \mu \mathrm{g}$ but there were also

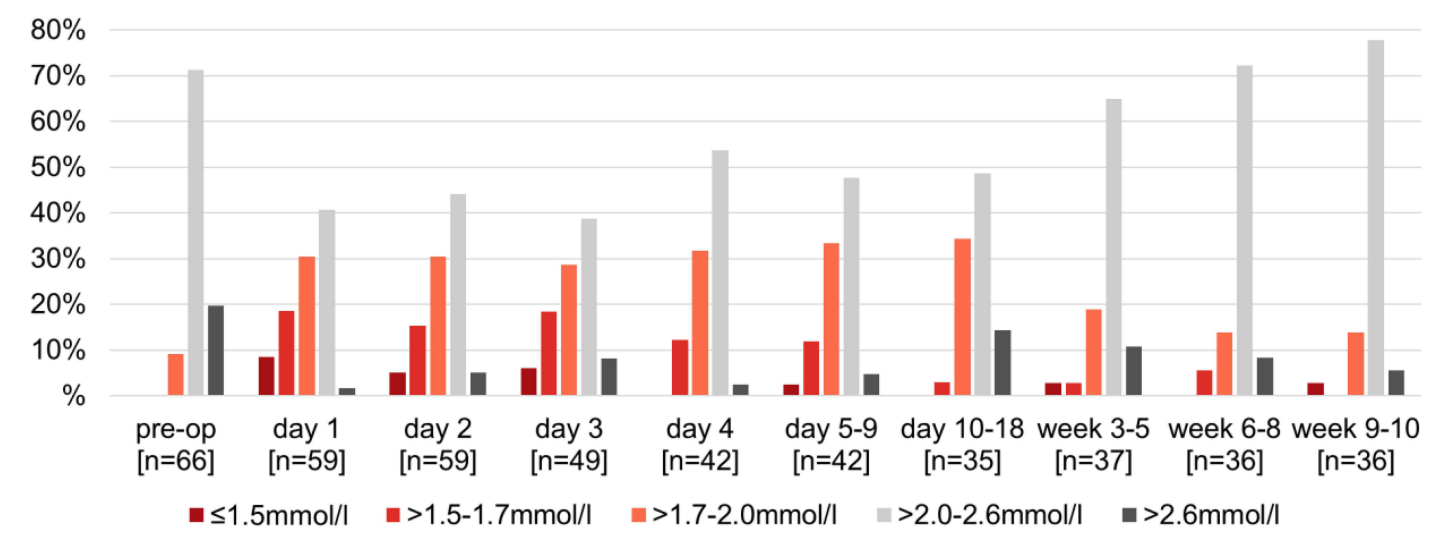

Figure 2 Calcium values within "high dose group".

Note: Analysis of calcium values during the ten postoperative weeks divided into hypo- or hypercalcemia. 


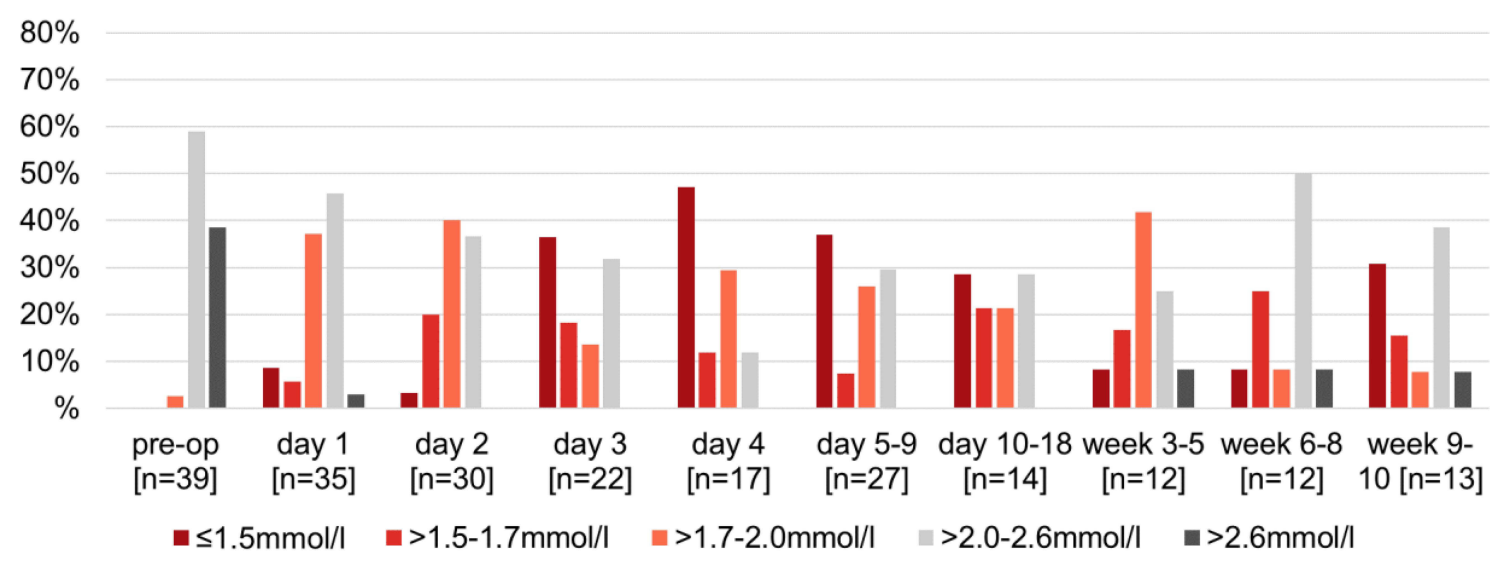

Figure 3 Calcium values within "low dose group".

Note: Analysis of calcium values during the ten postoperative weeks divided into hypo- or hypercalcemia.

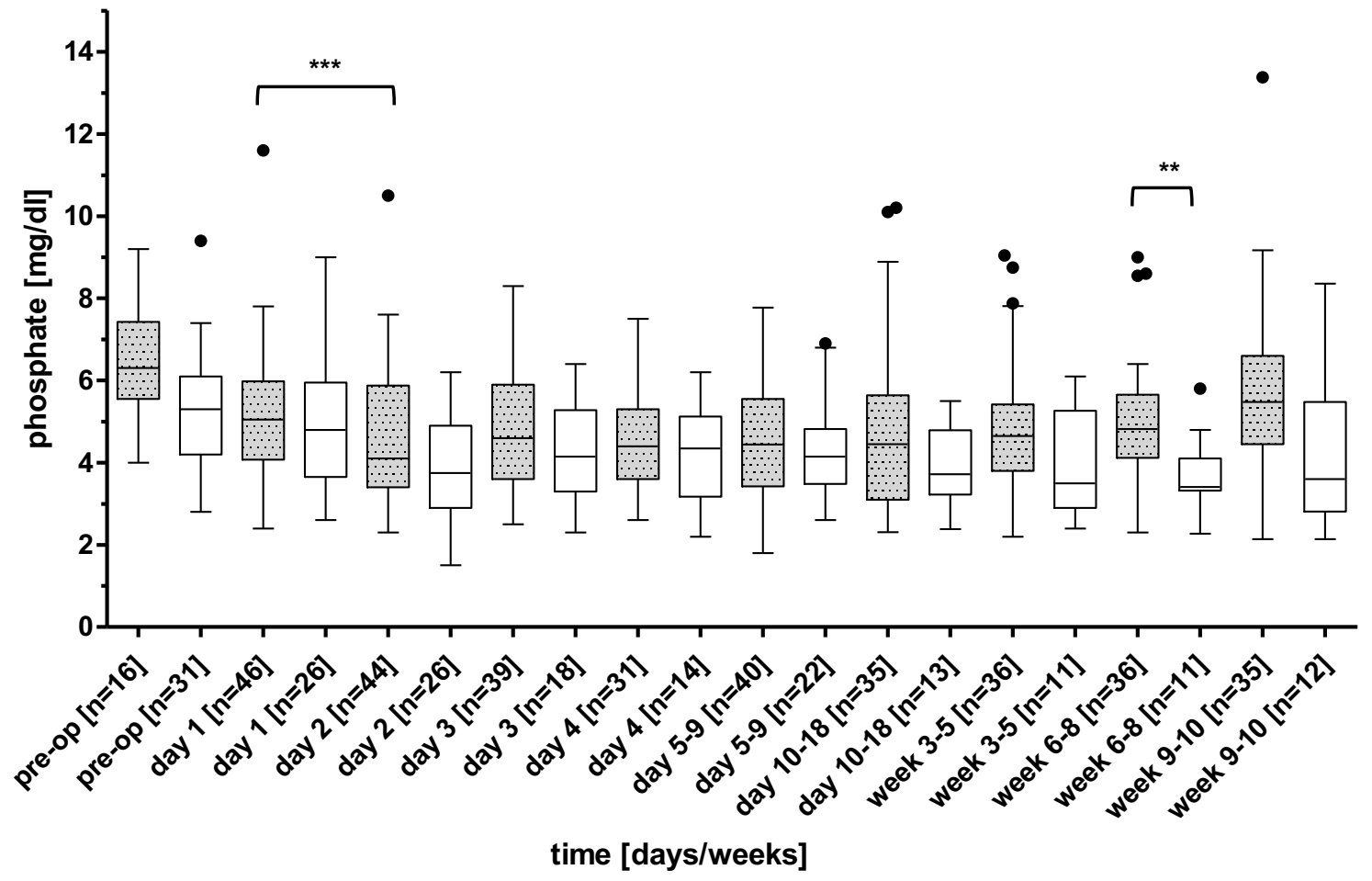

Figure 4 Boxplot phosphate course of the "high dose group" and "low dose group".

Notes: Black line = median; box = interquartile range; whisker = I.5 times IQR or minimum/maximum; dots = extreme outliers. "High dose group" is shown in grey; "Low dose group" is shown in white. Level of significance: $* * p<0.01$; ***p $<0.001$.

patients who still required $16 \mu \mathrm{g}$ alfacalcidol. Calcium acetate was initiated at $8550 \mathrm{mg}$ on days 1 and 2 and then adjusted appropriately. Calcium was substituted intravenously in $7.6 \%(n=67)$ of patients in the HDG, whereas $45.7 \%(\mathrm{n}=44)$ of LDG patients received intravenous calcium. During the first week postoperatively, citrate was used as an anticoagulant during hemodialysis and calcium was substituted intravenously during dialysis treatment (4-6 hours). In peritoneal dialysis patients calcium in the dialysis bag was increased from $1.25 \mathrm{mmol} / \mathrm{l}$ to $1.75 \mathrm{mmol} / \mathrm{l}$.

\section{Preoperative Treatment with Cinacalcet}

In our total cohort of 111 patients, 51 patients (45.95\%) received cinacalcet before surgery, We analyzed differences between those groups for the course of calcium, 


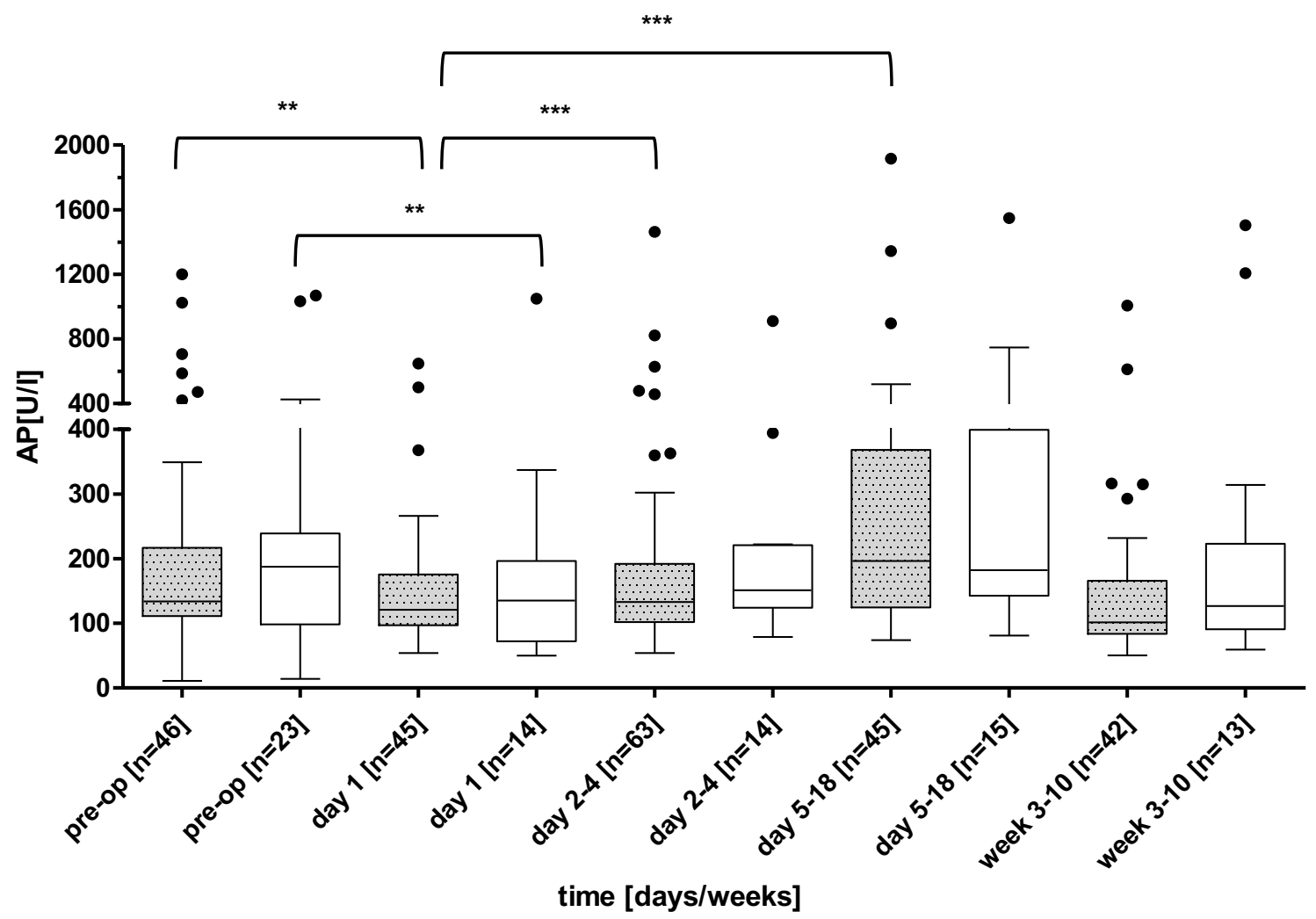

Figure 5 Boxplot alkaline phosphatase course of the "high dose group" and "low dose group".

Notes: Black line = median; box = interquartile range; whisker = I.5 times IQR or minimum/maximum; dots = extreme outliers. "High dose group" is shown in grey; "Low dose group" is shown in white. Level of significance: **p $<0.01$; ***p $<0.001$.

phosphate, AP and PTH but could not find any significance. Our data demonstrated no influence of preoperative cinacalcet administration on the postoperative course in any of the parameters.

\section{Discussion}

In patients undergoing PTx for sHPT, the period after surgery is characterized by a presumed drop in calcium and PTH. Our findings suggest, that higher doses of alfacalcidol and calcium acetate reduce both the incidence and the degree, as well as the timing of hypocalcemia.

Our data on the postoperative course of PTH fall in line with data from previous studies. A drop in PTH due to the removal of the glands is often used as an indicator for successful surgery. ${ }^{17,22-24}$ As a consequence, calcium is shifted from the blood into the bone leading to hypocalcemia.

The incidence of hypocalcemia after PTx ranges between $27 \%$ and $83 \%{ }^{13,17,25}$ Our results were similar, where $57.6 \%$ of the HDG and $82.2 \%$ of the LDG developed hypocalcemia $(<2.0 \mathrm{mmol} / \mathrm{l})$ within the first days. The administration of active vitamin $\mathrm{D}$ (calcitriol or alfacalcidol) reduces the incidence of hypocalcemia. It has long been known that postoperative treatment with calcitriol impacts serum calcium levels. ${ }^{15}$ As a transcription factor for a calcium-binding protein that transports calcium and phosphate ions across intestinal epithelial cells, calcitriol stimulates the uptake of calcium in the intestine, thus raising serum calcium levels. ${ }^{26}$ Clair et al compared patients receiving calcitriol to patients receiving a placebo within the first 14 days after PTx and detected a lower rate of hypocalcemia and less need for calcium supplements in patients receiving calcitriol. ${ }^{15}$ Further investigations about the role of calcitriol were done by Niramitmahapanya et al who compared three groups receiving different regimens of calcitriol: "fixed dose" of calcitriol, "titrated dose" of calcitriol against serum calcium level and "loaded dose" of calcitriol, with loading of 2.25-4 $\mu \mathrm{g} /$ day at first postoperative day. Concerning serum calcium they showed that patients receiving "the loaded" dose required significant less intravenous calcium gluconate than those in the "titrated dose" group. ${ }^{19}$ Based on this finding our study affirms previous approaches about the role of high-dosage vitamin D after 


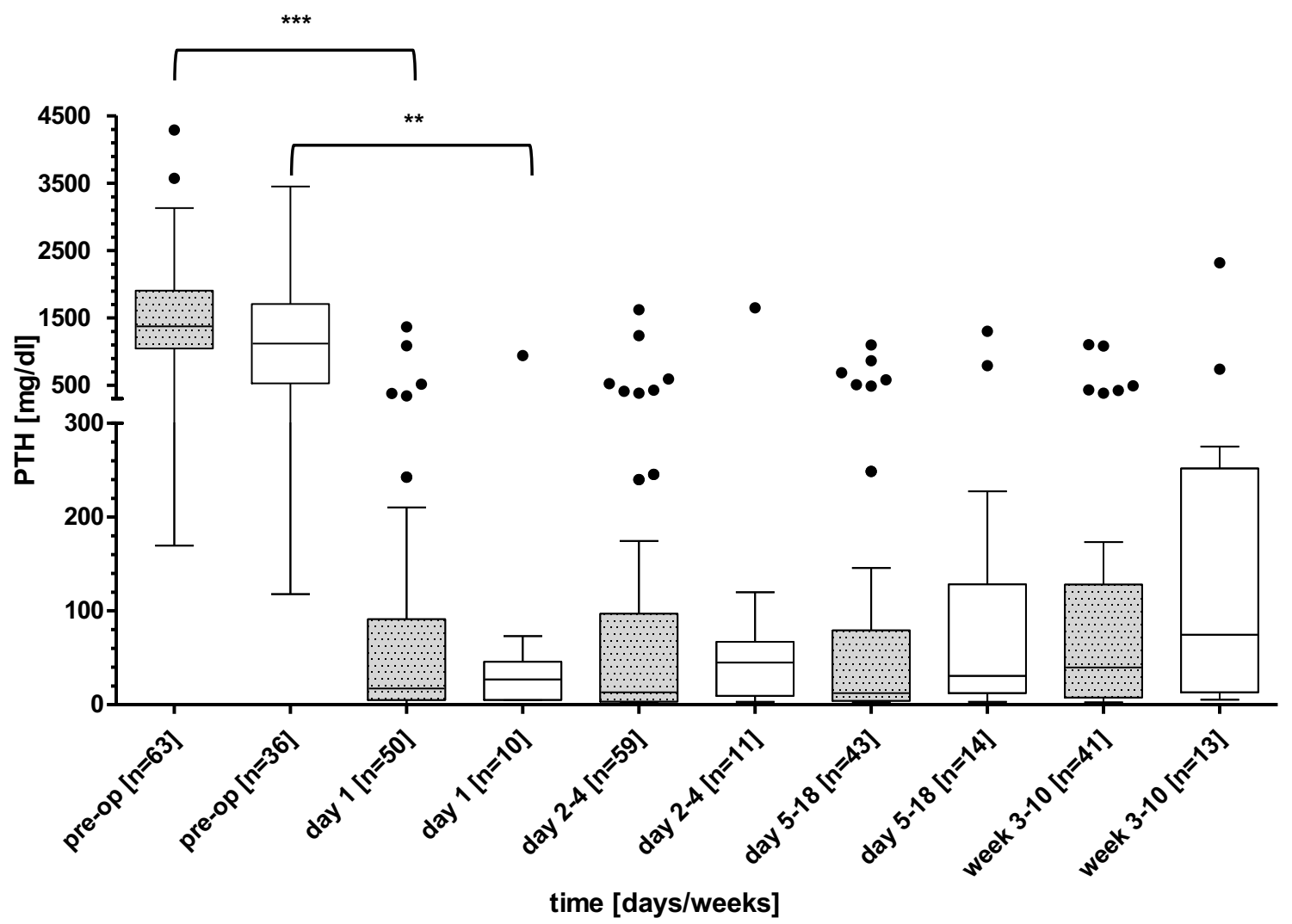

Figure 6 Boxplot parathyroid hormone course of the "high dose group" and "low dose group".

Notes: Black line = median; box = interquartile range; whisker = I.5 times IQR or minimum/maximum; dots = extreme outliers. "High dose group" is shown in grey; "Low dose group" is shown in white. Level of significance: $* * p<0.01$; ***p $<0.001$.

PTx but as far as we know, calcitriol has only been applied at doses up to $4 \mu \mathrm{g}$ per day. ${ }^{15,20,23,25}$ In our HDG given 12 $\mu \mathrm{g}$ alfacalcidol, the percentage of patients who developed serum calcium values $<1.5 \mathrm{mmol} / \mathrm{l}$ was significantly lower than in the group given less alfacalcidol. The frequency of severe hypocalcemia was considerably lower in the HDG, and more of those patients had calcium levels within the reference range (2.0-2.6 mmol/l) compared to the LDG. There are no data in the literature to compare these results about the degree of hypocalcemia, but our data suggest that applying high doses of alfacalcidol reduces the severity of hypocalcemia. In terms of the time of onset of hypocalcemia, it seems that high-dosage alfacalcidol treatment improves the development of hypocalcemia in that it

Table 3 Postoperative Alfacalcidol Dose Within “High Dose Group”

\begin{tabular}{|c|c|c|c|c|c|}
\hline & $\mathbf{n}$ & Mean $[\mu g] \pm$ SD & $\operatorname{Min}[\mu g]$ & $\operatorname{Max}[\mu \mathrm{g}]$ & $\mathbf{p}$ \\
\hline Day I-2 & 67 & $12,00 \pm 0$ & $12(n=67)$ & $12(n=67)$ & \\
\hline Day 3-4 & 67 & $11,29 \pm 1.92$ & $2,5(n=1)$ & $12(n=57)$ & $<0.01 * *$ \\
\hline Day 5-6 & 67 & $10,08 \pm 3.79$ & I $(n=2)$ & $16(n=4)$ & $<0.001 * * *$ \\
\hline day $7-9$ & 54 & $9,25 \pm 4.88$ & I $(n=2)$ & $20(n=1)$ & $<0.001 * * *$ \\
\hline Day 10-18 & 40 & $7,63 \pm 4.49$ & $0(n=1)$ & $16(n=3)$ & $<0.001 * * *$ \\
\hline Week 3-5 & 28 & $4,47 \pm 3.58$ & $0(n=1)$ & $16(n=1)$ & $<0.001 * * *$ \\
\hline Week 6-8 & 17 & $3,71 \pm 4.24$ & $0(n=2)$ & $16(n=1)$ & $<0.001 * * *$ \\
\hline Week 9-10 & 13 & $4,77 \pm 4.49$ & $0(n=2)$ & $16(n=1)$ & $<0.01 * *$ \\
\hline
\end{tabular}

Notes: Listed are mean \pm SD, minimum $(\min )$ and maximum $(\max )$ dose of alfacalcidol of the verum group. Values are given in $\mu g /$ day. Changes over time were analysed by Wilcoxon test, using the first postoperative day as the reference value. A significant reduction compared with the first postoperative day was evident from the third postoperative day onward ( $*^{*} \mathrm{p}<0.01$, *** $\mathrm{p}<0.00 \mathrm{I}$ ). Differences in the size of the collective are indicated as $\mathrm{n}$. 
appears significantly earlier compared to lower dose alfacalcidol (day 1 in HDG vs day 4 in LDG). In those studies investigating postoperative calcium courses within the first 14 days: the nadir of mean calcium levels after PTx occurs even later, between the 9th and 14th postoperative day. ${ }^{15,17,25}$

Recent studies have investigated the prevention of hypocalcemia by starting to apply calcitriol before surgery. The ideas of this approach rely on the assumption that calcitriol needs 24 hours until its effect occurs. ${ }^{21,25}$ This could be an approach worth taking to optimize the therapy with high-dose alfacalcidol and to prevent hypocalcemia that appears especially within the first postoperative days. The restrained use of calcitriol after PTx in previous studies could be due to considering that administering more than $2 \mu \mathrm{g}$ calcitriol per day leads to supraphysiological serum levels and thus has no additional effect. We cannot judge this from our study, we did not measure the 1.25 OH D2 level, however, one would expect significantly higher incidence of hypercalcemia from supraphysiological levels. ${ }^{17}$ Hypercalcemia occurred in $14.3 \%$ of our HDG within the 3rd week with a maximum of 3.32 $\mathrm{mmol} / \mathrm{l}$, compared to $8.3 \%$ of our LDG with a maximum of $2.86 \mathrm{mmol} / \mathrm{l}$. Thus, we should be aware of this side effect, and serum calcium and AP should be measured closely in order to adjust the alfacalcidol and calcium acetate supplementation appropriately.

The approach, indication and timing of calcium supplementation differ among authors. Some start intravenous calcium substitution immediately after surgery and slowly reduce it according to serum calcium levels. ${ }^{17,25}$ Others administer calcium orally immediately after PTx at doses ranging from 1 to $3 \mathrm{~g}$ calcium per day and reserve intravenous application for severe hypocalcemia $(<7.0 \mathrm{mg} / \mathrm{dl})$ or the appearance of severe hypocalcaemic symptoms such as numbness, paresthesia or tetany. ${ }^{17,20,23,24}$ Calcium is straightforward, and an efficient way to resolve hypocalcemia but patient adherence is often quite poor because of side effects like diarrhea, and intravenous application implies a prolonged hospital stay. ${ }^{16}$ Our results show that by high-dosage vitamin D therapy, the need for additional intravenous calcium application is significantly reduced. Only $7.6 \%$ of our HDG patients compared to $41-90 \%$ in previous studies required intravenous calcium. ${ }^{9,16,20,21}$

Hungry bone disease after PTx is often associated with a longer hospital stay. ${ }^{25,27,28}$ Although the duration of hospital stay did not differ statistically (median 5 (HDG) vs 6 days
(LDG)) almost a quarter of the LDG patients had to stay longer than 8 days, whereas only $5 \%$ of the HDG patients did.

Despite the application of phosphate chelators, our data reveal the influence of active vitamin $\mathrm{D}$ on the phosphate course. Patients receiving high doses of alfacalcidol present slightly higher phosphate levels, which probably reflects the increased absorption of phosphate via the gastrointestinal tract. ${ }^{26}$ Previous data show a postoperative drop in phosphate during the first 14 days, followed by a gradual increase, still measuring values within the reference range. ${ }^{9,25}$ The phosphate-lowering effect of phosphate chelators is most likely overwhelmed by the high alfacalcidol dose.

$\mathrm{AP}$ as a bone remodeling parameter does not seem to be affected either by doses of calcitriol up to $2 \mu \mathrm{g}$ per day ${ }^{29}$ or by high doses of alfacalcidol. An increase in AP is observed between days 5 and 18, which is consistent with data from studies where an increase was observed between the first and second week. ${ }^{7,17,25}$ Those data suggest that increased bone formation occurs in the period after PTx. This remodeling process is most active after two weeks, but then subsides. ${ }^{29}$

The present study has certain limitations: we designed a retrospective single-center study, and the number of the patients in the control group (LDG) was limited. Other parameters might also have been helpful, eg, measuring of 25-OH Vitamin D levels in order to discuss the influence of vitamin D deficiency on the outcome of HBS, and serum levels of $1.25 \mathrm{OH}$ Vitamin D in the presence of the high-dose alfacalcidol administration.

\section{Abbreviations}

AP, alkaline phosphatase; PTH, parathyroid hormone; PTx, parathyroidectomy; CKD, chronic kidney disease; MBD, mineral bone disorder; sHPT, secondary hyperparathyroidism; HDG, high dose group; LDG, low dose group.

\section{Summary}

The period after PTx in CKD stage 5 patients is characterized by an assumed drop in calcium and PTH within the first days. Ongoing high bone turnover is observed in the second and third weeks. This study shows that therapy with high-dose alfacalcidol immediately after surgery improves serum calcium levels, while significantly reducing episodes of severe hypocalcemia $(<1.5 \mathrm{mmol} / \mathrm{l})$; moreover, the need for intravenous calcium application is far less pronounced. Nevertheless, patients must be closely monitored in order to avoid overtreatment resulting in hypercalcemia. 
We hope that our findings will help optimize management strategies to prevent symptomatic hypocalcemia and prolonged hospital stays.

\section{Data Sharing Statement}

The datasets used and/or analyzed during the current study are available from the corresponding author on reasonable request.

\section{Ethics Approval and Informed Consent}

The study was approved by the local ethics committee of the University Duisburg-Essen (16-70-40-BO). The patients gave written informed consent. This study was conducted in accordance with the Declaration of Helsinki.

\section{Author Contributions}

$\mathrm{MG}, \mathrm{WR}, \mathrm{FW}$, and AK designed the study. MG acquired data. ALK and NM analyzed Data. All authors interpreted the data. MG and WR wrote the manuscript. All authors critically reviewed the manuscript. All authors agreed on the journal to which the article was submitted. All authors reviewed and agreed on all versions of the article before submission, during revision, the final version accepted for publication, and any significant changes introduced at the proofing stage. All authors take responsibility and are accountable for the contents of the article.

\section{Disclosure}

Prof. Dr. Andreas Kribben report personal fees from Ablynx NV, grants, personal fees from Advitos, grants, personal fees, support of symposium from Alexion Pharma $\mathrm{GmbH}$, support of symposium from Amgen, grants, personal fees, support of symposium from Astellas Pharma $\mathrm{GmbH}$, personal fees from Astra Zeneca $\mathrm{GmbH}$, personal fees from Baxter Deutschland, personal fees, support of symposium from Bayer Vital $\mathrm{GmbH}$, support of symposium from B Braun Avitum, support of symposium from Binding Site, grants from BMS, grants from Cendres + Metaux SA, grants from Charite Berlin, personal fees, support of symposium from Chiesi $\mathrm{GmbH}$, personal fees from Cyto Sorbents Europe, grants from Exthera Medical, personal fees from GE Healthcare, grants, support of symposium from GlaxoSmithKline $\mathrm{GmbH}$, grants from InflaRx $\mathrm{GmbH}$, support of symposium from Janssen Cilag $\mathrm{GmbH}$, grants from KKS Dresden, personal fees from MVZ Usedom, support of symposium from Kyowa Kirin $\mathrm{GmbH}$, support of symposium from Neovii Biotech $\mathrm{GmbH}$, grants, personal fees, support of symposium from Novartis Pharma $\mathrm{GmbH}$, grants, personal fees, support of symposium from Otsuka Pharma GmbH, support of symposium from Peripal, personal fees, support of symposium from Pfizer Pharma GmbH, grants from Reata, grants, personal fees, support of symposium from Sanofi Aventis, support of symposium from Shire Takeda $\mathrm{GmbH}$, support of symposium from Syneos Health $\mathrm{GmbH}$, grants from UK Münster, support of symposium from Vifor Fresenius, outside the submitted work. The authors report no other conflicts of interest in this work.

\section{References}

1. Levin A, Bakris GL, Molitch M, et al. Prevalence of abnormal serum vitamin D, PTH, calcium, and phosphorus in patients with chronic kidney disease: results of the study to evaluate early kidney disease. Kidney Int. 2007;71(1):31-38. doi:10.1038/sj.ki.5002009

2. Block GA, Klassen PS, Lazarus JM, Ofsthun N, Lowrie EG, Chertow GM. Mineral metabolism, mortality, and morbidity in maintenance hemodialysis. JASN. 2004;15(8):2208-2218. doi:10.1097/01. ASN.0000133041.27682.A2

3. Tentori F, Zepel L, Fuller DS, et al. The DOPPS practice monitor for US dialysis care: PTH levels and management of mineral and bone disorder in US hemodialysis patients. Am J Kidney Dis off $J$ Nat Kidney Found. 2015;66(3):536-539. doi:10.1053/j.ajkd.2015.07.011

4. Yajima A, Inaba M, Tominaga Y, Ito A. Bone formation by minimodeling is more active than remodeling after parathyroidectomy. Kidney Int. 2008;74(6):775-781. doi:10.1038/ki.2008.242

5. Kidney Disease: Improving Global Outcomes (KDIGO) CKD-MBD Update Work Group. KDIGO 2017 clinical practice guideline update for the diagnosis, evaluation, prevention, and treatment of chronic kidney disease-mineral and bone disorder (CKD-MBD). Kidney Int Suppl. 2017;7(1):1-59. doi:10.1016/j.kisu.2017.04.001

6. Young EW, Albert JM, Satayathum S, et al. Predictors and consequences of altered mineral metabolism: the dialysis outcomes and practice patterns study. Kidney Int. 2005;67(3):1179-1187. doi:10.1111/j.1523-1755.2005.00185.x

7. Zhang Y, Lu Y, Feng S, Zhan Z, Shen H. Evaluation of laboratory parameters and symptoms after parathyroidectomy in dialysis patients with secondary hyperparathyroidism. Ren Fail. 2019;41 (1):921-929. doi:10.1080/0886022X.2019.1666724

8. Pihlstrøm H, Dahle DO, Mjøen G, et al. Increased risk of all-cause mortality and renal graft loss in stable renal transplant recipients with hyperparathyroidism. Transplantation. 2015;99(2):351-359. doi:10.1097/TP.0000000000000583

9. Latus J, Roesel M, Fritz P, et al. Incidence of and risk factors for hungry bone syndrome in 84 patients with secondary hyperparathyroidism. Int J Nephrol Renovasc Dis. 2013;6:131-137. doi:10.2147/IJNRD.S47179

10. Lau WL, Obi Y, Kalantar-Zadeh K. Parathyroidectomy in the management of secondary hyperparathyroidism. CJASN. 2018;13 (6):952-961. doi:10.2215/CJN.10390917

11. Schlosser K, Zielke A, Rothmund M. Medical and surgical treatment for secondary and tertiary hyperparathyroidism. Scand J Surg. 2004;93(4):288-297. doi:10.1177/145749690409300407

12. Wang M, Chen B, Zou X, et al. A nomogram to predict hungry bone syndrome after parathyroidectomy in patients with secondary hyperparathyroidism. J Surg Res. 2020;255:33-41. doi:10.1016/j. jss.2020.05.036 
13. Kritmetapak K, Kongpetch S, Chotmongkol W, Raruenrom Y, Sangkhamanon S, Pongchaiyakul C. Incidence of and risk factors for post-parathyroidectomy hungry bone syndrome in patients with secondary hyperparathyroidism. Ren Fail. 2020;42(1):1118-1126. doi:10.1080/0886022X.2020.1841655

14. Yifei G, Yang G, Wang N, et al. Bone metabolism markers and hungry bone syndrome after parathyroidectomy in dialysis patients with secondary hyperparathyroidism. Int Urol Nephrol. 2019;51 (8):1443-1449. doi:10.1007/s11255-019-02217-y

15. Clair F, Leenhardt L, Bourdeau A, et al. Effect of calcitriol in the control of plasma calcium after parathyroidectomy. A placebo-controlled, double-blind study in chronic hemodialysis patients. Nephron. 1987;46(1):18-22. doi:10.1159/000184289

16. Florescu MC, Islam KM, Plumb TJ, Smith-Shull S, Nieman J, Mandalapu P. Calcium supplementation after parathyroidectomy in dialysis and renal transplant patients. Int J Nephrol Renovasc Dis. 2014;7:183-190. doi:10.2147/IJNRD.S56995

17. Viaene L, Evenepoel P, Bammens B, Claes K, Kuypers D, Vanrenterghem Y. Calcium requirements after parathyroidectomy in patients with refractory secondary hyperparathyroidism. Nephron Clin Pract. 2008;110(2):c80-5. doi:10.1159/000151722

18. Pal R, Gautam A, Bhadada SK. Role of bisphosphonates in the prevention of postoperative hungry bone syndrome in primary hyperparathyroidism: a meta-analysis and need for randomized controlled trials. Drug Res. 2021;71(2):108-109. doi:10.1055/a-1325-0351

19. Goldfarb M, Gondek SS, Lim SM, Farra JC, Nose V, Lew JI. Postoperative hungry bone syndrome in patients with secondary hyperparathyroidism of renal origin. World J Surg. 2012;36 (6):1314-1319. doi:10.1007/s00268-012-1560-x

20. Niramitmahapanya S, Sunthornthepvarakul T, Deerochanawong C, Sarinnapakorn V, Athipan P. Role of loading calcitriol to control hypocalcemia after parathyroidectomy in chronic kidney disease. J Med Assoc Thailand. 2011;94(3):295-302.
21. Alsafan S, Shermann SK, Dahdaleh FS, et al. Preoperative calcitriol reduces postoperative intravenous calcium requirements and length of stay in parathyroidectomy for renal-origin hyperparathyroidism. Surgery. 2019;165(1):151-157. doi:10.1016/j.surg.2018.03.029

22. Puccini M, Carpi A, Cupisti A, et al. Total parathyroidectomy without autotransplantation for the treatment of secondary hyperparathyroidism associated with chronic kidney disease: clinical and laboratory long-term follow-up. Biomed Pharmacother. 2010;64(5):359-362. doi:10.1016/j.biopha.2009.06.006

23. Schneider R, Slater EP, Karakas E, Bartsch DK, Schlosser K. Initial parathyroid surgery in 606 patients with renal hyperparathyroidism. World J Surg. 2012;36(2):318-326.

24. Stracke S, Jehle PM, Sturm D, et al. Clinical course after total parathyroidectomy without autotransplantation in patients with end-stage renal failure. Am J Kidney Dis. 1999;33(2):304-311. doi:10.1016/S0272-6386(99)70305-7

25. Ho L-Y, Wong P-N, Sin H-K, et al. Risk factors and clinical course of hungry bone syndrome after total parathyroidectomy in dialysis patients with secondary hyperparathyroidism. BMC Nephrol. 2017;18(1):12. doi:10.1186/s12882-016-0421-5

26. Dusso AS, Brown AJ, Slatopolsky E, Vitamin D. Vitamin D. Am $J$ Physiol Renal Physiol. 2005;289(1):F8-F28. doi:10.1152/ ajprenal.00336.2004

27. Shih M-L, Duh Q-Y, Hsieh C-B, et al. Total parathyroidectomy without autotransplantation for secondary hyperparathyroidism. World J Surg. 2009;33(2):248-254. doi:10.1007/s00268-008-9765-8

28. Ishani A, Liu J, Wetmore JB, et al. Clinical outcomes after parathyroidectomy in a nationwide cohort of patients on hemodialysis. CJASN. 2015;10(1):90-97. doi:10.2215/CJN.03520414

29. Mazzaferro S, Chicca S, Pasquali M, et al. Changes in bone turnover after parathyroidectomy in dialysis patients: role of calcitriol administration. Nephrol Dialysis Transpl. 2000;15(6):877-882. doi:10.1093/ndt/15.6.877
The International Journal of Nephrology and Renovascular Disease is an international, peer-reviewed open-access journal focusing on the pathophysiology of the kidney and vascular supply. Epidemiology, screening, diagnosis, and treatment interventions are covered as well as basic science, biochemical and immunological studies. The manuscript management system is completely online and includes a very quick and fair peer-review system, which is all easy to use. Visit http://www.dovepress.com/testimonials.php to read real quotes from published authors. 